\title{
SISTEM PAKAR DIAGNOSA PENYAKIT KANKER PAYUDARA MENGGUNAKAN METODE FORWARD CHAINING DAN DEPTH FIRST SEARCH
}

\author{
Permadi, Harun Mukhtar,Budi Arhaml \\ Fakultas Ilmu Komputer Universitas Muhammadiyah Riau
}

\begin{abstract}
Abstrak- Kanker payudara merupakan salah satu kanker berbahaya yang sudah banyak menimbulkan korban. Di Indonesia kanker payudara menduduki peringkat kedua setelah kanker leher rahim.Untuk mengatasinya perlu dihindari faktor resiko yang menyebabkan kanker payudara serta melakukan pemeriksaan payudara secara rutin untuk mengetahui adanya indikasi kanker payudara dan membantu masyarakat untuk mengurangi biaya konsultasi ke dokter yang masih mahal.Oleh karena itu, dibuatlah Aplikasi Diagnosa Dini pada Penyakit Kanker Payudara Berbasiskan Sistem pakar yang dapat digunakan untuk membantu mendeteksi adanya penyakit kanker payudara dalam tubuh seseorang. Aplikasi ini berbasis web yang dapat diakses setiap saat sehingga mendukung pemeriksaan rutin yang bisa dilakukan oleh diri sendiri. Proyek akhir ini dibuat dengan menggunakan metode penalaran forward chaining, dan metode penelusuruan depth first search diimplementasikan dengan menggunakan bahasa pemrograman PHP, sedangkan untuk knowledge base menggunakan database MySQL. Dengan adanya aplikasi ini, pengetahuan yang dimiliki oleh pakar mengenai kanker payudara dapat tersusun dalam knowledge base dalam bentuk basis data yang digunakan pada aplikasi ini. Hasil dari tugas akhir ini berupa sebuah halaman web yang dapat digunakan untuk membantu masyarakat diagnosa dini penyakit kanker payudara.
\end{abstract}

Kata Kunci : sistem pakar, kanker payudara, forward chaining,depth first search, MySQL, PHP

\section{Pendahuluan}

Sistem Pakar adalah Sistem yang berusaha mengadopsi pengetahuan manusia ke komputer, agar komputer dapat menyelesaikan masalah seperti yang biasa dilakukan para ahli. Sistem Pakar tidak untuk menggantikan para ahli tetapi memasyarakatkan pengetahuan dan pengalaman pakar tersebut. Sistem Pakar dalam dunia kesehatan biasanya digunakan untuk konsultasi, analisis, diagnosis, membantu pengambilan keputusan dan lain-lain. Salah satu dari kegunaan sistem pakar adalah untuk mendiagnosa penyakit kanker.

Kanker adalah pembelahan sel yang tidak terkendali sehingga menyerang jaringan biologis yang lain. Kanker payudara merupakan jenis dari penyakit kanker yang paling banyak diderita oleh perempuan yang memiliki keganasan sehingga mampu menimbulkan kematian. Saat ini kanker payudara merupakan penyebab kematian kedua pada wanita setelah kanker leher rahim. Menurut Organisasi Kesehatan Dunia (WHO) tahun 2012 penderita penyakit kanker payudara sekitar 32\% dari jumlah wanita didunia. Setiap tahun lebih dari 425.000 kasus baru yang terdiagnosa kanker payudara dan 300.000 dari penderita kanker payudara meninggal dunia. Hal ini membutuhkan penanganan yang cepat dan serius pada saat ditemukan agar dapat dilakukan pemulihan secara medis dan terapis. Sebenarnya kanker bukanlah penyakit yang tidak bias disembuhkan, akan tetapi bila diketahui lebih dini maka dapat diobati dengan tepat sehingga kanker dapat disembuhkan. Keterbatasan ekonomi untuk berkonsultasi kedokter serta minimnya pengetahan masyarakat atau perempuan tentang penyakit kanker payudara menjadi alasan keterlambatan penanganan kanker payudara. Berdasarkan permasalahan tersebut dibangunlah sebuah Aplikasi Sistem Pakar untuk mendiagnosa penyakit kanker payudara, sehingga dapat 
membantu masyarakat untuk mendiagnosa penyakit kanker payudara yang dialami nya.

Kebutuhan informasi dan diagnosa yang cepat dan tepat mengenai kanker payudara sangatlah dibutuhkan, oleh karena permasalahan tersebut maka akan dibangun sistem pakar untuk mendiagnosis penyakit kanker payudara berbasiskan web agar dapat membantu masyarakat untuk diagnosa penyakit kanker payudara.

\section{Kajian Pustaka}

\section{a. Kanker Payudara}

Menurut Yayasan Kanker Indonesia (YKI) kanker adalah suatu kondisi dimana sel telah kehilangan pengendalian dan mekanisme normalnya, sehingga mengalami pertumbuhan yang tidak normal, cepat dan tidak terkendali. Kanker payudara (Carcinoma mammae) didefinisikan sebagai suatu penyakit neoplasma yang ganas yang berasal dari parenchyma. Saat ini kanker payudara merupakan penyebab kematian kedua pada wanita setelah kanker leher rahim dan merupakan kanker yang paling banyak ditemui pada wanita.

Setiap risiko kanker payudara pada wanita dapat mempunyai kemungkinan yang lebih tinggi atau lebih rendah, bergantung pada beberapa faktor yang meliputi riwayat keluarga, genetik, usia saat menstruasi pertama dan faktor-faktor lainnya. Ketika wanita dengan usia lebih muda terkena kanker payudara, maka akan cenderung perkembangan kanker tersebut lebih agresif dibandingkan wanita yang usia nya lebih tua. Hal inilah yang mungkin menjelaskan mengapa angka harapan hidup pada wanita usia muda lebih rendah. Kanker payudara tidak menyerang kulit payudara yang berfungsi sebagai pembungkus. Kanker payudara menyababkan sel dan jaringan payudara berubah bentuk menjadi abnormal dan bertambah banyak secara tidak terkendali.

\section{b. Perkembangan dan Pertumbuhan Kanker Payudara}

Kanker payudara di bagi menjadi beberapa stadium: (Rumah sakit kanker dharmais, 2002) a. Stadium I

Berupa sebuah benjolan yang biasanya dirasakan berbeda dari jaringan payudara disekitarnya, tidak menimbulkan nyeri dan biasanya memiliki pinggiran yang tidak teratur.

b. Stadium II

Pada stadium ini, apabila benjolan pada payudara didorong oleh jari tangan,benjolan bisa digerakan dengan mudah dibawah kulit.

c. Stadium III

Pada stadium ini, benjolan biasanya melekat pada dinding dada atau kulit disekitarnya. Bisa berbentuk benjolan yang membengkak atau borok dikulit payudara. Kadang kulit diatas benjolan mengkerut dan tampak seperti kulit jeruk. Gejala lain yang mungkin ditemukan adalah benjolan atau massa diketiak, perubahan ukuran atau bentuk payudara. Keluar cairan seperti abronormal dari putting susu (biasanya berdarah atau berwarna kuning sampai hijau, mungkin juga bernanah), perubahan pada warna atau tekstur kulit pada payudara, putting susu maupun areola (darah berwarna coklat tua disekitar outing susu). Payudara tampak kemerahan, kulit disekitar puting susu bersisik, putting susu tertarik kedalam atau terasa gatal, nyeri payudara atau pembengkakan salah satu payudara.

d. Stadium IV

Pada stadium lanjut bisa timbul nyeri tulang, penurunan berat badan, pembengkakan atau ulserasi kulit.

\section{c. Kecerdasan Buatan}

Kecerdasan buatan adalah suatu ilmu yang mempelajari cara membuat komputer melakukan sesuatu seperti yang dilakukan oleh manusia. Ada tiga tujuan kecerdasan buatan, yaitu: membuat komputer lebih cerdas, mengerti tentang kecerdasan, dan membuat mesin lebih berguna. Yang dimaksud kecerdasan adalah kemampuan untuk belajar atau mengerti dari pengalaman, memahami pesan yang kontradiktif dan ambigu, menanggapi dengan cepat dan baik atas situasi yang baru, menggunakan penalaran dalam 
memecahkan masalah serta menyelesaikannya dengan efektif.

\section{d. Sistem Pakar (Expert Sistem)}

Sistem pakar adalah suatu program komputer yang dirancang untuk mengambil keputusan seperti keputusan yang diambil oleh seseorang atau beberapa orang pakar. Dalam penyusunannya, sistem pakar mengkombinasikan kaidah-kaidah penarikan kesimpulan (inference rules) dengan basis pengetahuan tertentu yang diberikan oleh satu atau lebih pakar dalam bidang tertentu. Kombinasi dari kedua hal tersebut disimpan dalam komputer, yang selanjutnya digunakan dalam proses pengambilan keputusan untuk penyelesaian masalah terterntu.

Adapun ciri-ciri sistem pakar diantaranya adalah (Kusrini, 2006):

a. Pengambilan keputusan berdasarkan kaidah-kaidah tertentu dan dapat merespon masukkan user melalui kotak dialog.

b. Dapat menalar data-data yang tidak pasti dan memberikan beberapa alasan pemilihan.

c. Terbatas pada bidang yang spesifik.

d. Outputnya berupa saran atau anjuran.

\section{e. Inferensi}

Inferensi merupakan suatu proses untuk menghasilkan informasi dari fakta yang diketahui atau diasumsikan. Inferensi adalah konklusi logis (logical conclusion) atau implikasi berdasarkan informasi yang tersedia. Dalam sistem pakar, proses inferensi dilakukan dalam suatu modul yang disebut Inferece Engine (Mesin Inferensi). Ketika representasi pengetahuan telah lengkap, atau paling tidak telah berada pada level yang cukup akurat, maka representasi pengetahuan tersebut telah siap digunakan. Inference Engine merupakan modul yang berisi program tentang bagaimana mengendalikan proses reasoning. Reasoning adalah proses bekerja dengan pengetahuan, fakta dan strategi pemecahan masalah untuk mengambil suatu kesimpulan (berpikir dan mengambil kesimpulan).

\section{f. Tree}

Untuk menghindari kemungkinan adanya proses pelacakan suatu node secara berulang, maka digunakan struktur tree. Struktur tree digunakan untuk menggambarkan keadaan secara hirarkis. Pohon juga terdiri dari beberapa node. Node yang terletak pada level0 disebut juga "akar". Node akar menunjukkan keadaan awal yang biasanya merupakan topik atau objek. Node akar ini terletak pada level ke0 . Node akar mempunyai beberapa percabangan yang terdiri atas beberapa node successor yang sering disebut dengan nama "anak" dan merupakan node-node perantara. Namun jika dilakukan pencarian mundur, maka dapat dikatakan bahwa node tersebut memiliki predecessor. Node-node yang tidak mempunyai anak sering disebut dengan nama node "daun" yang menunjukkan akhir dari suatu pencarian, dapat berupa tujuan yang diharapkan (goal) atau jalan buntu (dead end) (Robert, 2008).

\section{g. Runut Maju (Forward Chaining)}

Runut maju berarti menggunakan himpunan aturan kondisi-aksi. Dalam metode ini, data digunakan untuk menentukan aturan mana yang akan dijalankan, kemudian aturan tersebut dijalankan. Mungkin proses menambahkan data ke memori kerja. Proses diulang sampai ditemukan hasil (Kusrini, 2006)

Forward chaining bisa disebut juga proses pencarian yang dimotori data (data driven search) yang dimulai dari premis-premis atau informasi masukan (if) dahulu kemudian menuju konklusi atau kesimpulan (then).

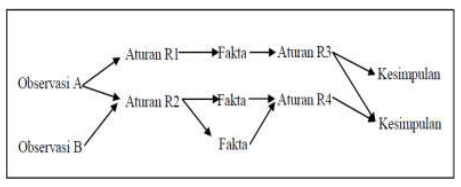

Gambar 1 Proses Forward Chaining

Forward Chaining merupakan suatu proses yang berdasarkan data dan fakta, dimana pengguna harus memberikan data atau fakta sebelum mesin inferensi bekerja atau melakukan proses. Mesin Inferensi menelususri basis pengetahuan sesuai data atau fakta yang 
diberikan untuk menghasilkan suatu kesimpulan akhir.

\section{h. Depth first search (DFS)}

Metode penelusuran yang digunakan pada sistem pakar ini adalah metode Depth first search (DFS), dimana sistem pakar ini akan menguji basis pengetahuan yang dimilikinya (dalam bentuk tree) mulai dari kiri setiap levelnya, jika kaidah pada basis pengetahuan yang diujinya tersebut benar, maka kaidpada level berikutnya lagi yang akan diuji. Sedangkan ketika kaidah yang diujinya tersebut salah, maka kaidah yang berada disampingnya (masih dalam 1 level yang sama) yang akan diujinya (Jogiyanto,2003). Untuk lebih jelas dapat dilihat pada Gambar 2.4 berikut ini.

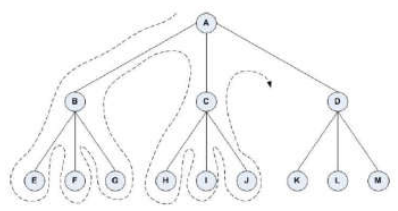

Gambar 2 Diagram Pohon dari DFS

\section{i. Penelitian Terdahulu}

Sistem pakar ini memiliki beberapa referensi dari review penelitian terdahulu terhadap skripsi dimana review tersebut berguna untuk memberikan masukkan dan ide untuk pembuatan Skripsi yang akan dibuat. Berikut adalah beberapa referensi dari review penelitian terdahulu:

Tabel 1 Penelitian Terdahulu

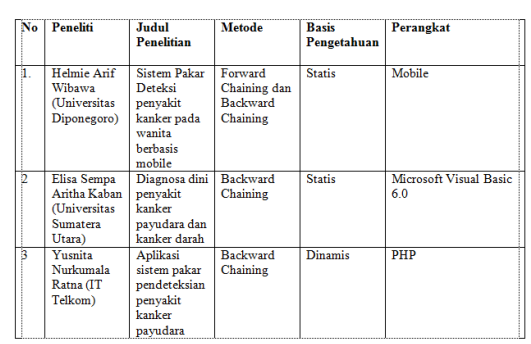

\section{Metodologi Penelitian}

\section{a. Pengumpulan Data}

Dalam Melakukan pengumpulan data dilakukan beberapa teknik cara mengumpulkan informasi tersebut yaitu:

a. Studi Pustaka

Melakukan Studi pustaka dengan membaca dan memahami buku yang berhubungan dengan sistem pakar yang akan dibuat dan browsing di internet untuk mendapat data dan informasi yang diperlukan untuk sistem yang akan dibuat.

b. Penelitian Lapangan

Melakukan wawancara dengan Dokter bedah kanker Dr.Effif Syofra Tripriadi,SPB.SPB(K) di Rumah Sakit Umum Arifin Achmad untuk menentukan gejala yang di alami oleh penderita penyakit kanker payudara serta solusi yang diberikan sesuai dengan hasil diagnosa.

\section{b. Analisis}

Setelah dilakukan pengumpulan data maka dilakukanlah analisis dari data yang diperoleh sesuai dengan permasalahan yang diteliti. Kebutuhan analisis meliputi sumber data diperlukan untuk menghasilkan informasi, karena informasi pada dasarnya merupakan hasil pengolahan data yang diinputkan pada sistem.

\section{c. Perancangan Sistem Pakar}

Sebelum membuat sebuah sistem, maka diperlukan suatu perancangan yang dapat membantu dalam mempermudah penyelesaian sistem yang akan dibangun dan dalam proses pembuatan dapat diselesaikan dengan cepat dan terstruktur. Pada tahap ini dilakukan perancangan dengan beberapa tahap, yaitu:

1. Perancangan UML

2. Perancangan Tabel

3. Perancangan User Interface

\section{d. Implementasi}

Pembuatan atau implementasi sistem pakar ini dilakukan setelah langkah-langkah perancangan sistem pakar selesai dilakukan. Dimana akan diterapkan segala yang ada dalam 
perancangan yang telah dijelaskan sebelumnya, dan mengimplementasikannya ke dalam bentuk program aplikasi yang dapat berjalan sesuai dengan tujuan yang diinginkan dan memenuhi kebutuhan dari user pengguna sistem.

\section{e. Pengujian}

Setelah pembuatan Sistem Pakar ini selesai dibuat, maka sistem yang telah dibangun tersebut sebaiknya dilakukan pengujian yang berguna untuk mengetahui apakah pekerjaan pemrograman telah dilakukan secara benar sehingga bisa menghasilkan fungsi-fungsi yang dikehendaki. Pengujian juga dimaksudkan untuk mengetahui keterbatasan dan kelemahan program apakah aplikasi yang dibuat untuk sebisa mungkin dilakukan penyempurnaan.

Hal-hal yang akan dilakukan dalam pengujian dari sistem ini adalah pengujian tiaptiap proses yang dilakukan seperti pengujian proses input dan output data pada sistem dan pengujian validasi data yang dihasilkan akan membuktikan apakah sistem berjalan sesuai kebutuhan.

\section{Hasil dan Pembahasan}

\section{a. Analisis}

Berikut adalah beberapa kebutuhan sistem pakar yang akan digunakan untuk penelusuran gejala sehingga penyakit dapat diketahui. Dalam melakukan analisis ada beberapa kebutuhan yang diperlukan oleh sistem antara lain:

\section{b. Kebutuhan Fungsional}

Kebutuhan fungsional merupakan kebutuhan fungsi yang bisa dilakukan oleh sistem sehingga pengguna mengerti kegunaan sistem yang akan dibangun. Adapun kebutuhan fungsional dari sistem meliputi:

1. Administrator dapat mengelola data dokter.

2. Administrator dapat mengelola data penyakit.
3. Administrator dapat mengelola data gejala.

4. Administrator dapat mengelola data kaidah.

5. Administrator dapat mengelola data gejala penyakit.

6. Administrator dapat melakukan upload gambar tree penyakit.

7. Member dapat melakukan diagnosa.

8. Member dapat melihat hasil diagnosa.

9. Member dapat melihat informasi penyakit.

10. Member dapat melihat informasi dokter.

\section{c. Arsitektur Sistem Pakar Diagnosa Penyakit Kanker Payudara}

Komponen utama pada arsitektur sistem pakar meliputi: antarmuka atau user interface yaitu hubungan atara user dengan sistem atau program, jawaban, motor inferensi atau tree, rencana solusi, fasilitas penjelasan, fakta dan aturan kanker payudara, penyaring pengetahuan, rekayasa pengetahuan, dokter atau pakar. Komponen ini dapat dilihat pada Gambar 4.1 berikut:

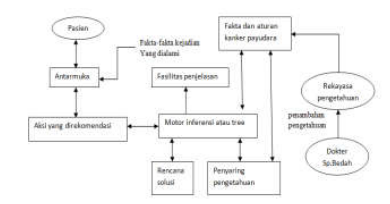

Gambar 3 Arsitektur SP Penyakit Kanker Payudara

\section{d. Forward Chaining}

Berdasarkan dari gejala dan nama penyakit maka terbentuklah sebuah aturan atau kaidah, dimana kaidah tersebut dapat digambarkan kedalam sebuah inferensi tree. Inferensi ini menelusuri gejala yang paling ringan ke gejala yang mendekati penyakit kanker payudara. Penelusuran ini berjalan dengan penelusuran DFS dengan menelusuri gejala dari kiri kemudian ke kanan, dimana gejala yang paling mendekati kanker payudara terletak di sub tree bagian kanan yang ditunjukkan pada gambar dibawah ini. 


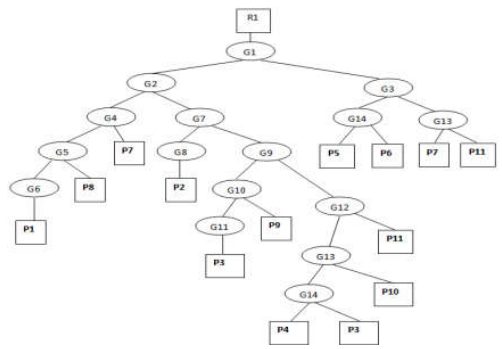

Gambar 4. Tree Penyakit Kanker Payudara

Dari Gambar 4 dapat dijelaskan mengenai gejala atau fakta-fakta dan penyakit yang saling berhubungan pada rule diagnosa penyakit kanker payudara.

1. Tabel penyakit

Tabel penyakit merupakan nama-nama penyakit yang berhubungan dengan kanker payudara.

Tabel 2. Penyakit

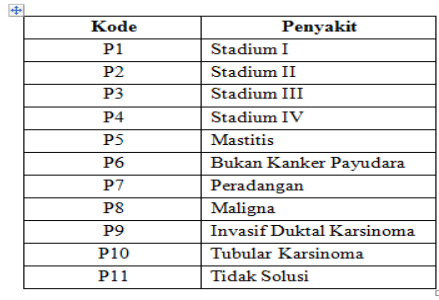

2. Tabel gejala

Tabel gejala merupakan nama-nama gejala yang dirasakan oleh penderita kanker payudara.

Tabel 3 Gejala

\begin{tabular}{|c|l|}
\hline Kode & \multicolumn{1}{|c|}{ Gejala } \\
\hline G1 & Benjolan di payudara \\
\hline G2 & Benjolan $\leq 2$ \\
\hline G3 & Payudara terasa nyeri \\
\hline G4 & Benjolan tidak nyeri \\
\hline G5 & Pinggiran benjolan teratur \\
\hline G6 & Benjolan Bergerak \\
\hline G7 & Benjolan $>2$ dan $\leq 5$ \\
\hline G8 & Benjolan Melekat \\
\hline G9 & Benjolan $>5$ dan $\leq 7$ \\
\hline G10 & Payudara berubah tekstur \\
\hline G11 & Borok dan cairan di Payudara \\
\hline G12 & Benjolan $>7$ \\
\hline G13 & Nyeri Tulang \\
\hline G14 & Lengan Bengkak \\
\hline
\end{tabular}

3. Tabel rule

Tabel rule merupakan penjelasan mengenai aturan atau kaidah yang berjalan pada Gambar 4
Tabel 4. Tabel Rule

\begin{tabular}{|c|c|}
\hline Kaitas 1 & IF G1 = Troe THEN Sob Tree Kaibain 2 \\
\hline Kaitas 2 & IF G1 = Troe THEN Sob Tree Kaidah 3 \\
\hline Kaitah 3 & IF G4 = Troe THEN Sob Tree Kaidah 4 \\
\hline Kaidas 4 & IF GS = True THEN Sab Tree Kaidah 5 \\
\hline Kaidah 5 & IF G6 = True THEN CONCLUSION P1 \\
\hline Kaidah 6 & IF G1 = Falve THEN Sob Tres Kaidoh ? \\
\hline Kaidas ? & IF G3 = Tros THEN Sob Tres haibah 9 \\
\hline Kaidas 3 & IF G14 = Trve THEN CONCLUSTON \\
\hline Kaidah 9 & IF G14 = Falbe THEN CONCLUSTON \\
\hline Kaisah 10 & IF G3 = Faloe THEN Sob Tree baidah \\
\hline Kaidas 11 & IF G13 = Troe THEN CONCLUSTON \\
\hline Kaidas 12 & IF G13 = Falve THEN CONCLUSTON \\
\hline Kaidas 13 & IF G4 = Falbe THEN CONCLUSTON \\
\hline Kaisan 14 & IF GS = Falbe THEN CONCLUSION \\
\hline Kaidas 15 & IF G2 = Falve THEN Sob Tree Kaidah \\
\hline Kaisah 16 & IF G? = True THEN Sob Tree Kaidah \\
\hline Kaicon 17 & IF GS = TrDe THEN CONCLUSION P2 \\
\hline Kaidah 18 & IF G? = Falve THEN Sob Tree Kaidah \\
\hline Kaidah 19 & IF G9 = Troe THEN Sob Tree Kaidah \\
\hline Kaidas 20 & IF G10 = True THEN Sob Tree Kaidah \\
\hline Kaisah 21 & IF G11 = TrVe THEN CONCLUSION \\
\hline Kaisah 22 & IF G10 = False THEN CONCLUSTON \\
\hline Kaisah 23 & IF G9 = Falve THEN Sab Tree kaifah \\
\hline Kaitas 24 & IF G12 = Troe THEN Sob Tree Kaisah \\
\hline Kaisan 25 & IF G13 = True THEN Sob Tree Kaidah \\
\hline Kaisas 26 & IF G14 = Troe THEN CONCLUSION \\
\hline Kaidah 27 & IF G12 = False THEN CONCLUSTON \\
\hline Kaidah 28 & IF G13 = False THEN CONCLUSION \\
\hline & \\
\hline
\end{tabular}

\section{e. Perancangan}

\section{Perancangan Use Case}

Use case adalah gambaran fungsionalitas dari suatu sistem, sehingga pengguna sistem paham dan mengerti mengenai kegunaan sistem yang akan dibangun. Perancangan use case dalam sistem ini menggambarkan apa yang akan dilakukan oleh pengguna. Dalam sistem ini pengguna terdiri dari member dan administrator. Untuk lebih jelas perancangan use case dapat dilihat pada Gambar berikut 


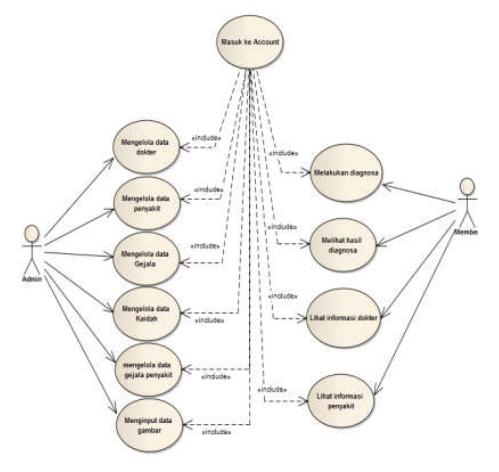

Gambar 5 Use Case

\section{Implementasi}

Implementasi adalah tahap dimana menerapkan segala yang ada dalam perancangan yang telah dijelaskan sebelumnya, dan mengimplementasikannya ke dalam bentuk program aplikasi yang dapat berjalan sesuai dengan tujuan yang diinginkan dan memenuhi kebutuhan dari user pengguna sistem.

\section{Tampilan Home User}

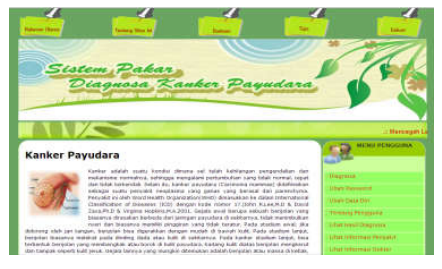

Gambar 6 Halaman Home User

\section{Tampilan Menu Diagnosa}

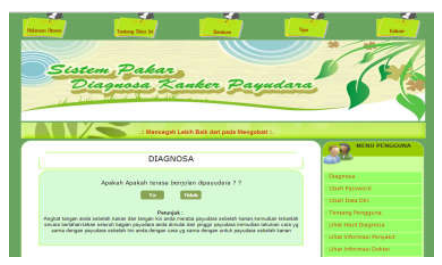

Gambar 7. Menu Diagnosa

\section{f. Pengujian}

Pada tahap pengujian ini berdasarkan hasil lapangan dengan kasus Ibu Lia dan setelah dilakukan pemeriksaan dengan dokter Effif Syofra Tripriadi,SpB.SpB(K)Onk maka hasil tersebut dibandingkan dengan hasil pengujian sistem untuk melihat ketepatan hasil sistem pakar diagnosa penyakit kanker payudara. Dijelaskan pada tree Gambar 8.

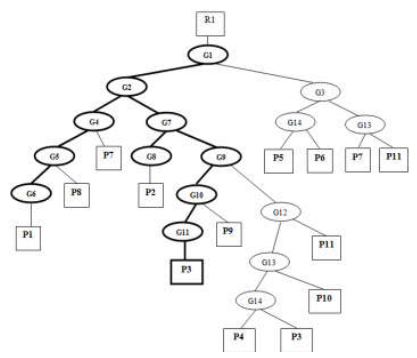

Gambar 8. Tree Penelusuran Manual

Dari Gambar 8 dapat dijelaskan nama-nama gejala dan penyakit pada Tabel 5 .

\begin{tabular}{|c|c|}
\hline G1 & Memiliki benjolan di payudara \\
\hline G2,G7,G9 & Memiliki beberapa benjolan di payudara \\
\hline G4 & Benjolan tidak nyeri \\
\hline G5 & Pinggiran benjolan teratur \\
\hline G6 & Benjolan dapat digerakkan dengan \\
\hline G8 & Benjolan tidak melekat \\
\hline G10 & Payudara berubah tekstur \\
\hline G11 & Borok di payudara \\
\hline P3 & Kanker Payudara Stadium III \\
\hline
\end{tabular}

Untuk pembuktian sistem pakar ini, Ibu Lia sebagai user harus menjawab setiap pertanyaan dengan benar sesuai dengan gejala yang dirasakan. Hal ini dapat dilihat dari beberapa gambar dibawah ini.

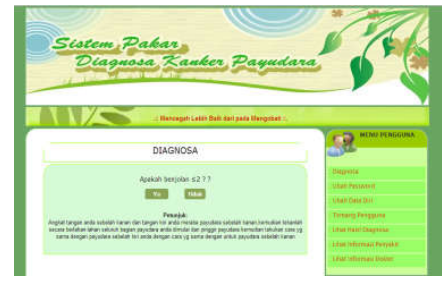

Gambar 9 Pertanyaan Jumlah Benjolan Pada Payudara 